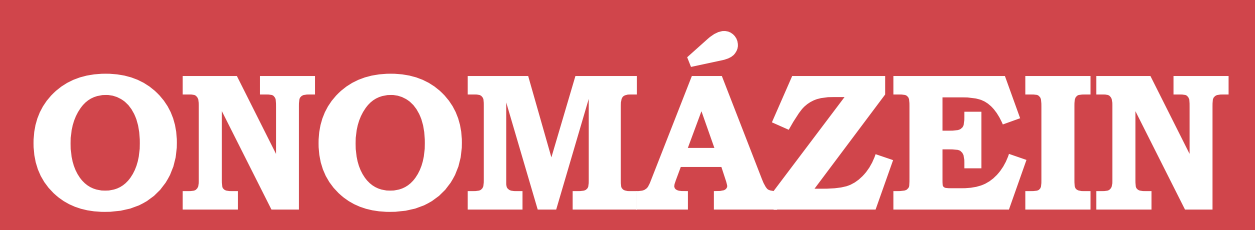

Revista semestral de lingüística, filología y traducción
PONTIFICIA UNIVERSIDAD

\title{
Orosio: tradición y revolución en la historiografía latina
}

Orosius: tradition and revolution in Latin historiography

\section{Catalina Balmaceda}

Pontificia Universidad Católica de Chile Chile

\section{(c) $(i)$}




\section{Resumen}

Este artículo trata sobre la obra historiográfica de Orosio, historiador cristiano, en el contexto de su época, a principios del siglo $V$ d. C. Lo que se intenta mostrar es que Orosio escribe sus Historias de una manera profundamente ligada a la tradición grecorromana en cuanto a forma y contenido, pero totalmente revolucionaria en la interpretación. Al igual que los historiadores de la antigüedad, busca proporcionar un recuerdo de los hechos importantes del pasado, entregarnos un juicio moral y presentar su obra como un escrito elegante utilizando para esto las herramientas de la retórica. Sin embargo, el autor no se detiene en una simple narración de hechos, sino que además los interpreta, buscando demostrar que los historiadores paganos no han sido capaces de entender el mensaje subyacente de la historia: para Orosio la historia de Roma es al mismo tiempo historia universal e historia cristiana y es precisamente en este punto donde radica la originalidad de su trabajo.

Palabras clave: Orosio; escritura histórica; retórica; cristianismo.

\section{Abstract}

This article deals with the historiographical work of Orosius, Christian historian, in the context of his own times, at the beginning of fifth century AD. I argue that Orosius wrote his Histories closely linked to the GrecoRoman tradition in style and content, but totally revolutionary in interpretation. Like the ancients historians, he seeks to remind us important facts of the past, to pass moral judgment and write elegantly using rheto- rical tools. However, the author not only narrates facts, but he also provides an interpretation of them, seeking to demonstrate that pagan historians have not been able to understand the underlying message of history: for Orosius, Roman history stands for universal and Christian history at the same time, and it is precisely in this point were the originality of his work lies.

Keywords: Orosius; historical writing; rhetoric; Christianity. 
1.

Existen pocos datos ciertos sobre la vida del sacerdote hispano Orosio. Ni siquiera su nombre es seguro: algunos señalan que el "Orosius P." de Jordanes se referiría a Orosius Paulus, pero otros señalan que sería más bien una referencia a su condición de presbítero (Jordanes, Getica, 9). La mayor parte de la información la encontramos en su propia obra historiográfica junto con otras pocas referencias en las cartas de san Agustín a Jerónimo y en los escritos de Genadio de MarseIla y Braulio de Zaragoza. Se cree que era original de Bracara - actual Braga, en Portugal-ciudad que pertenecía a la provincia de Galicia, pero otros autores, siguiendo la frase Tarraconem nostram del mismo Orosio, apoyan la tesis de que habría nacido en la Hispania Tarraconensis del Imperio romano (Orosio, Adv. Pag. 7.22.8). En todo caso, su origen en la península hispánica no es discutido y la teoría de que habría nacido en Braga es la más aceptada por las alusiones en las cartas 166 y 169 que hace San Agustín de que Orosio llegaba a África desde las costas del Océano Atlántico y no por el Mediterráneo: “... Orosio, un joven presbítero muy santo y estudioso, que llegó acá desde el fin de España, es decir, desde las playas del Océano”. Las fechas de su nacimiento y muerte tampoco se conocen con precisión, pero por los cálculos que se pueden hacer por estas mismas cartas de Agustín y las propias referencias de Orosio en sus Historias se estima que habría vivido entre el 383 y el 420 d. C. ${ }^{2}$

Orosio debe haber pertenecido a una familia de buena posición social pues su obra refleja una esmerada educación, sobre todo en los clásicos grecolatinos y en retórica. Al parecer Orosio tuvo que salir de Bracara a raíz de las invasiones germanas de principios del siglo $\vee$ d. C., situación que señala él mismo en su obra como una fuga dramática: "Me vi frente a frente con los bárbaros, a los que no había visto nunca, los esquivé cuando se dirigían hostiles hacia mí, los ablandé cuando se apoderaron de mí, les rogué a pesar de ser infieles y los burlé cuando me retenían, finalmente escapé de ellos cubierto de una repentina niebla cuando me perseguían en el mar, cuando trataban de alcanzarme con piedras y dardos, y cuando ya casi me alcanzaban con sus manos"3. La fecha exacta de este suceso no se sabe, pero sería alrededor del 414 d. C., cuando el mismo autor señala que habría llegado a Hipona para encontrarse con el mayor intelectual de la época, el obispo Agustín, para consultarle algunos puntos doctrinales respecto al origen del alma que estaban siendo atacados por los priscilianistas ${ }^{4}$. En la carta que más tarde le escribiría San Agustín a Jerónimo en Palestina le presenta al joven sacerdote:

Acá llegó Orosio, joven piadoso, hermano en la paz católica, hijo por edad y colega en el presbiterado por dignidad, despierto de ingenio, fácil de palabra, ardiente de afán. Codicia ser vaso útil en la casa de Dios, a fin de rebatir las falsas y perniciosas doctrinas que han asesinado las almas de los españoles con más aciago rigor que destrozó sus cuerpos la espada de las bárbaros (...). Luego le he enseñado cuanto he podido. Cuanto no he podido, le he mostrado cómo puede aprenderlo. Y, en fin, le he exhortado a ir a ti. Recibió con gusto y docilidad mi consejo o precepto. Entonces le rogué que a su vuelta regresara a la patria pasando por aquí. Ateniéndome a su promesa, pensé que Dios me deparaba esta ocasión de consultarte esos puntos que quiero conocer.

1 Agustín, Ep. 169:...cuiusdam sanctissimi et studiosissimi iuvenis presbyteri Orosii, qui ad nos ab ultima Hispania, id est, ab oceani littore. Y también Ep. 166: "Acá Ilegó Orosio (...) Desde la playa del Océano vino hasta mí [Nam inde ad nos usque ab oceani littore properavit]".

2 Cf. Orosio, Adv. Pag. 7.2.8. Para una más completa discusión al respecto, véase E. Sánchez-Salor, 1982: 7-19; C. Torres Rodríguez, 1985; J. Vilella, 2000: 94-121; A. Fear, 2010a: 1-6; P. van Nuffelen, 2012: 1-5.

3 Orosius, Adv. Pag. 3.20.6-7: ut ignotos primum barbaros viderim, ut infestos declinaverim, ut dominantibus blanditus sim, ut infideles praecaverim, ut insidiantes subterfugerim, postremo ut persequentes in mari ac saxis spiculisque adpetentes, manibus etiam paene iam adprehendentes repentina nebula circumfusus evaserim ...

4 A. Fear (2010a: 3) pone este suceso en el 411 d. C. 
Estaba yo buscando a quien enviar, y no hallaba fácilmente un sujeto idóneo por su fidelidad en el obrar, prisa en obedecer y práctica en viajar. En cuanto traté a este joven, no pude dudar de que era tal cual yo lo pedía a Dios 5 .

Orosio es presentado como un joven talentoso en quien Agustín confía y al que le encomendará una tarea delicada.

En el 415 d. C. Orosio emprende así la misión de viajar a Oriente para encontrarse con Jerónimo. El viaje a Palestina tenía un doble motivo: por una parte, Orosio quería tratar con san Jerónimo temas teológicos, especialmente los del origen del alma, y, por otra, entregar unas cartas de san Agustín, que quería estrechar lazos con san Jerónimo y recabar información sobre Pelagio y su herejía. Una vez instalado en Palestina, Orosio contribuyó con san Jerónimo en atacar esta doctrina, participando en el sínodo de Jerusalén en el año 415, donde arremetió fuertemente contra el pelagianismo. A fines de ese mismo año se encontraron en Palestina las reliquias de san Esteban y se le encomendó a Orosio la misión de llevar una parte de ellas a Braga (cf. P. Martínez Cavero, 2002: 43-5).

En el 416 Orosio deja Palestina y se embarca hacia Occidente, pasando antes por Jerusalén y Alejandría. De allí vuelve donde Agustín, le entrega las cartas de Jerónimo y le cuenta detalladamente su encuentro con Pelagio. Mientras estuvo en África, Orosio asistió al Concilio de Cartago en el 416 y luego habría iniciado el viaje de vuelta a su patria, pero al llegar a Menorca se entera de las guerras y devastaciones de los vándalos en España, por lo que tiene que abandonar las reliquias en la isla. En Menorca comenzaría una gran devoción a san Esteban que más tarde se dispersaría por toda la Galia e Hispania (cf. V. Gauge, 1998).
Se piensa que sería en esta segunda estancia en el norte de África cuando el obispo de Hipona le habría encargado al joven sacerdote que escribiera una historia del mundo que fuera una respuesta apologética al argumento pagano que postulaba que el advenimiento del cristianismo había sido la causa de todo tipo de males y desastres para el Imperio y el mundo entero, pues los hombres habrían dejado de adorar a los dioses romanos tradicionales. En esos precisos momentos, se les achacaba a los cristianos la responsabilidad del terrible saqueo de Roma por el godo Alarico pocos años antes, en el 410 d. C. Así nos cuenta Orosio que se gestó la Historiae adversus Paganos: "He obedecido tu mandato [praecepto], bienaventurado padre Agustín, y ojalá que lo haya hecho con tanta eficacia como buena voluntad. (...) Me ordenaste que escribiera contra la vana maldad de aquellos que, ajenos a la ciudad de Dios, son llamados paganos por los pueblos y villas de campo en que viven, o gentiles porque gustan de las cosas terrenas [Praeceperas mihi, uti adversus vaniloquam pravitatem eorum, qui alieni a civitate Dei ex locorum agrestium conpitis et pagis pagani vocantur sive gentiles quia terrena sapiunt] (...). [M]e ordenaste, pues, que, de todos los registros de historias y anales que puedan tenerse en el momento presente, expusiera en capítulos sistemáticos y breves de un libro todo lo que encontrase: ya desastres por guerras, ya estragos por enfermedades, ya desolaciones por hambre, ya situaciones terribles por terremotos, insólitas por inundaciones, temibles por erupciones de fuego volcánico o crueles por golpes de rayos o caída de granizo, o incluso las miserias ocurridas en siglos anteriores a causa de parricidios y otras ignominias" (Orosio, Adv. Pag. praef. 9-10).

Existen varias hipótesis sobre la fecha de composición de esta obra. La que propone una

5 Agustín, Ep. 166.2 (a Jerónimo). También hace alusión a Orosio en Ep. 169.13 (a Evodio): “No he querido perder la coyuntura que me ofrecía Orosio, un joven presbítero muy santo y estudioso, que llegó acá desde el fin de España, es decir, desde las playas del Océano, movido tan sólo por el afán de conocer las Santas Escrituras. Le persuadí a que visitase a Jerónimo. Este Orosio me hizo algunas preguntas que le inquietaban sobre la herejía de los priscilianistas y sobre algunas opiniones de Orígenes no aceptadas por la Iglesia. Contesté a sus preguntas con la brevedad y claridad que pude en un libro no grande. He escrito también un libro grande contra la herejía de Pelagio". 
fecha más temprana sugiere que Orosio habría empezado a escribir sus Historiae ya en su primera estancia en África, luego habría interrumpido el relato durante su viaje a Oriente y habría retornado a la escritura a su vuelta en el 416. Esta teoría tiene la ventaja de que se le otorgaría a Orosio un poco más de tiempo para realizar su investigación, pero no existe ninguna evidencia cierta para esto (cf. M. P. Arnaud-Lindet, 1990: xxii-xxv). La hipótesis más tradicional señala que Orosio habría compuesto su obra a la vuelta de su viaje a Palestina en el 416, terminándola en el 417, es decir, tardando poco más de un año en escribirla ${ }^{6}$. Esto no es tan imposible como parece a primera vista porque Orosio, como hombre culto y con vasta formación retórica, habría estado familiarizado con las obras historiográficas más significativas y también con sus epítomes, por lo que debe haber utilizado el material de manera muy expedita. Después de la publicación de sus Historiae, no tenemos más noticias de Orosio.

A pesar de la escasa información que se tiene de la vida de este historiador, es posible deducir algunos puntos importantes. Uno de ellos es el que nos lleva a tomar conciencia del nivel de comunicaciones que tenía el Imperio romano a principios del siglo $\mathrm{V}$ d. C. Primeramente vemos una comunicación a nivel físico o material: Orosio se mueve en un Imperio intercomunicado; es tiempo de agitadas invasiones bárbaras, pero el Imperio no se ve totalmente obstruido o cercado por ellas. Las vías marítimas siguen funcionando; se ve como normal y, sobre todo, posible dirigirse desde Galicia por el Atlántico al norte de África, de ahí a Palestina, luego volver pasando por Alejandría y Menorca y llegar de vuelta a Hipona. La Pax Romana de alguna manera sigue existiendo en el Mediterráneo, aunque no lo hará por mucho tiempo más. En un segundo nivel, se puede apreciar una rica comunicación intelectual o circulación en el plano de las ideas: Orosio, joven sacerdote hispano - tenía alrededor de 32 años-, viaja, conoce gente, establece redes con los grandes de su época. Sabe quién es Agustín y quiere ir a preguntarle cuestiones doctrinales. Por su parte, Agustín acoge a Orosio y lo envía a Palestina a hablar con Jerónimo, quien lo invita a participar del Sínodo de Jerusalén. Orosio llega a entrevistarse con Pelagio mismo y discute con él; conoce las doctrinas heréticas del priscilianismo y pelagianismo, se siente capaz de luchar contra ellas y se une a intelectuales poderosos para esto. Hay un pensamiento y un lenguaje cultural común que une tres continentes: Europa, África y Asia. Orosio se mueve, por un lado, en las coordenadas imperiales y, por otro, en las cristianas: son los dos ejes que marcan clara y definitivamente su vida. Lo que me propongo en las páginas siguientes es mostrar de qué manera estas coordenadas marcarían también con la misma fuerza su obra historiográfica originando un producto profundamente arraigado en la tradición, pero a la vez revolucionario en la interpretación.

2.

Se puede decir que la obra de Orosio es un ejemplo de fusión de los elementos clásicos de la historiografía grecorromana desarrollada en el Imperio y de la novedad que significa la interpretación cristiana de la historia. Orosio es un autor que actúa como "bisagra”; con su obra se despide del mundo antiguo, sin dejar completamente de pertenecer a él, y por otro lado presagia un cambio radical en la historiografía. Las Historiae adversus Paganos ponen a su autor como el primer historiador que escribe historia pagana con sentido cristiano (cf. A. Fear, 2010ab: passim). Y es en este punto donde el sacerdote hispano puede ser calificado como revolucionario.

Orosio es el primer historiador cristiano que escribe historia pagana porque él no escribe "his-

6 Cf. P. Martínez Cavero, 2002: 52-3; A. Fear, 2010a:7. G. Zecchini (2003: 320) sostiene (pero no lo demuestra) que Orosio habría terminado sus Historiae en el año 418. 
toria de la Iglesia" como lo había hecho Eusebio de Cesarea años antes, no escribe "historia del cristianismo" en un lugar determinado como lo haría Beda el Venerable para los anglos o Gregorio de Tours para los francos, y tampoco escribe "historia de la salvación" como lo estaba haciendo paralelamente su contemporáneo Agustín, que iba en ese entonces en la publicación del libro X de su Ciudad de Dios. La diferenciación de los géneros históricos juega aquí un papel importante. Frecuentemente se ha tendido a ver a todos los historiadores cristianos de la época tardoantigua como haciendo exactamente lo mismo, solo que unos con mejor y otros con peor resultado. Pero escribir "historia del cristianismo", por ejemplo, no era lo mismo que escribir "historia de la Iglesia". La primera se caracterizaba por la insistente recurrencia a los orígenes del mundo para situar ahí la raíz de lo que sería la religión cristiana, mientras que la "historia de la Iglesia" se centraba, por el contrario, en lo sucedido después de la venida de Cristo a la tierra, en especial lo ocurrido a sus seguidores en su misión expandiendo la doctrina. La "historia de la salvación", por otro lado, se trataba más exactamente de una interpretación de la historia otorgándole un sentido y llegaba a ser a veces, más bien, una "metahistoria". Orosio, en cambio, escribe la historia del mundo secular, narra los acontecimientos ocurridos en los distintos lugares y partes de la tierra sin distinción de su religión: le interesan todos los pueblos. Si bien todos estos subgéneros mencionados poseen unas características que los hacen distinguirse unos de otros, todos ellos son genuinos intentos de escribir verdadera "historia" por parte de sus autores, no de hacer una transposición de la teología en la historia ${ }^{8}$. Estos escritos pertenecen al género historiográfico y podría ser una sobresimplificación el encasillar todas las obras históri- cas cristianas, por el simple hecho de ser escritas por cristianos, como "apéndices" de una teología de la historia. Orosio escribe primeramente historia, obviamente desde un punto de vista cristiano, pero es historia y debemos situarla en el mismo contexto y siguiendo reglas similares a las que seguía la historiografía grecorromana. Es en este sentido que decimos que Orosio es fiel a una tradición consolidada.

En la obra Historiae adversus Paganos de Orosio se puede ver una primera intención que coincide con la de cualquier obra historiográfica griega o romana: proporcionar un recuerdo de los hechos importantes del pasado para rescatarlos del olvido; son las memoriae rerum gestarum. Su principal tarea era la de contar los acontecimientos del pasado tal como se habían llevado a cabo, es decir, otorgar un relato verdadero. Para esto era necesario el estudio y la indagación. Orosio se veía a sí mismo haciendo algo muy similar a sus predecesores; es más, en el prólogo de su obra señala que presenta una "investigación" [scrutatio] y es a partir de ella que se podrán aclarar los hechos ocurridos: "Por eso, a través de esta investigación queda claro... [ut merito hac scrutatione claruerit...]" (Orosio, Adv. Pag. praef. 14). Orosio sigue así tal cual la práctica que se había iniciado con Heródoto, que había presentado sus Historias de la misma manera: "Aquí Heródoto de Halicarnaso expone el resultado de sus averiguaciones"?.

Orosio se propone escribir historia secular del mundo y va siguiendo ordenadamente el recorrido de los reinos que han dominado la tierra hasta su presente, a inicios del siglo $\mathrm{V} \mathrm{d}$. C. La obra se compone de siete libros que se dividen de la siguiente manera: el primero va desde Adán, el primer hombre [ab Adam primo homine], hasta la fundación de Roma; el libro segundo llega

7 Para mayor detalle sobre este punto, véase J. Aurell, C. Balmaceda, P. Burke, F. Soza, 2013: 61-3

8 Cf. P. van Nuffelen, 2010: 171. Véase también P. van Nuffelen, 2012: passim, pero especialmente 3-5; Whitby, 2011.

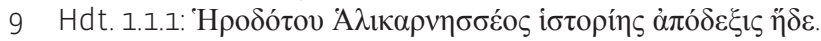


hasta el segundo saqueo de Roma por los galos en el 386 a. C.; el tercero, hasta la batalla de Sentino contra los samnitas en el 295 a. C. y las simultáneas guerras de los sucesores de Alejandro Magno en Oriente. El libro cuarto narra hasta la destrucción de Cartago en el 146 a. C. y el quinto hasta el periodo después de la dictadura de Sila, tratando también a Sertorio y Espartaco. El libro sexto cuenta la historia de Roma del siglo I a. C. hasta la Encarnación de Jesucristo y el séptimo relata desde el gobierno de Augusto abarcando todo el periodo imperial hasta el 417 d. C.

El hecho de que Orosio decida escribir sus Historiae en varios libros con contenido principalmente político lleva a pensar que el historiador quiso conscientemente tomar distancia de las típicas escuetas cronologías cristianas que se escribían en el momento ${ }^{10}$, que ordenaban sincrónicamente las fechas más importantes, y en cambio buscara alcanzar algo que cuadrara mejor dentro de la tradición de la historiografía clásica. Orosio, siguiendo los ideales de la exactitud y la precisión - distintivos propios de toda escritura histórica-, se basa en las mismas fuentes seculares que habían utilizado los historiadores griegos y romanos y, por eso, de hecho en su historia no hay grandes diferencias - salvo contadas excepciones - entre los relatos de Tucídides, Salustio, Tito Livio o Suetonio. Orosio no tiene problemas en reconocer y señalar explícitamente de dónde ha obtenido la información de lo que narra. Por ejemplo, cuando se refiere a la conjuración de Catilina es bastante escueto porque dice que contamos con los discursos de
Cicerón y la monografía de Salustio y su narración no difiere en nada de la de estos escritores: "Desde nuestro punto de vista es suficiente haber tocado brevemente esta historia [sc. la de Catilina] por cuanto ya es conocida con suficiencia por todos gracias a los discursos de Cicerón y a la narración de Salustio"11, y lo mismo señala para la guerra de Yugurta en Numidia: "En lo que se refiere a Yugurta, yo voy a resumir, sólo por razón del orden cronológico y por hacer alguna mención, algunas cosas con brevedad, por cuanto de su voluble e inaguantable forma de ser así como de sus dolosas y hábiles acciones todo el mundo tiene noticias suficientes gracias a la rica elegancia de estilo de los escritores"12. La conquista de las Galias, en cambio, que tiene una descripción directa bastante más larga de las ya mencionadas, Orosio dice que la toma de Suetonio: "Estos hechos los narró profusamente Suetonio Tranquilo, del que nosotros hemos sacado apropiado resumen"13.

Orosio no solo sigue a los historiadores clásicos en el tratamiento de la temática, sino que también suscribe algunas de sus importantes ideas políticas o estratégicas; una de ellas es la del metus hostilis". El saludable "temor al enemigo" había sido la visión tradicional de la política externa romana avalada nada menos que por Escipión y combatida por Catón el Censor:

Algunos romanos decidieron que se debía destruir Cartago en pro de la seguridad perpetua de Roma; otros pensaban, sin embargo, que se debía permitir a Cartago permanecer incólume en su estado en pro de la eterna preocupación de los

10 Como la de Julio Africano, Eusebio o Jerónimo, por ejemplo.

11 Orosio, Adv. Pag. 6.6.6: sed hanc historiam agente Cicerone et describente Sallustio satis omnibus notam nunc a nobis breviter fuisse perstrictam sat est.

12 Orosio, Adv. Pag. 5.15.2: Sed ego de Iugurtha ordinis tantum loco et causa commemorationis breviter perstrinxerim, quia ut de natura eius varia atque intolerabili ita et de rebus tam dolose quam strenue gestis propter opimam scriptorum luculentiam satis sufficiens apud omnes notitia est.

13 Orosio, Adv. Pag. 6.7.2: Hanc historiam Suetonius Tranquillus plenissime explicuit, cuius nos conpetentes portiunculas decerpsimus. Sin embargo, el nivel de detalle de la narración y las semejanzas con La guerra de las Galias de Julio César hacen parecer poco probable que haya sido sólo Suetonio la fuente principal de estos episodios; cf. Suet. Caes. 25.

14 La idea era común en el pensamiento antiguo y aparece en Jenofonte, Platón, Aristóteles y Polibio (Jen. Cir. 3, 1, 26; Platón, Leyes 3.698; Arist. Pol. 7.1334 a-b; Polib. 6.18). Un tema central también para los historiadores romanos, entre ellos, Salustio, pues en concreto explicaba el origen de la decadencia de la república romana: cf. Sal. BJ 41.2; Hist. 1.12. Véase también T. Livio, 1.19.4; Vel. Pat. 2.1.1. 
valores romanos, que estaban siempre en función de la sospecha de rivalidad de otra ciudad, para que, de esta forma, el vigor romano, alimentado siempre con las guerras, no se relajara con la tranquilidad y el ocio y cayera en una lánguida indolencia (Orosio, Adv. Pag. 4.23.9).

Una vez que el temor al enemigo hubo desaparecido con la destrucción definitiva de Cartago en la tercera guerra púnica, Roma se vio sin incentivos reales para guardar su disciplina y mantener sus virtudes tradicionales; el fin del metus hostilis significó la llegada de una serie de influencias perniciosas para los romanos que serían difíciles de extirpar: el amor por el lujo, el ocio, el deseo de dinero y de poder. Salustio lo había expuesto claramente en su Conjuración de Catilina:

Pero cuando por esfuerzo y justicia la República creció, fueron dominados por la guerra grandes reyes, sometidos por la fuerza naciones salvajes y pueblos ingentes, Cartago, émula del poder romano, desapareció de raíz y todos los mares y tierras estaban abiertos, comenzó a mostrarse cruel la fortuna y a alterar todas las cosas. Quienes habían soportado fácilmente esfuerzos, peligros, situaciones dudosas y complicadas, para estos el ocio y las riquezas - cosas deseables en otras circunstancias - sirvieron de carga y miseria. Así pues, primero creció el ansia de poder, después de dinero; estas cosas fueron como la raíz de todos los males. Pues la avaricia aniquiló la lealtad, la honradez y restantes buenas artes; en lugar de estas enseñó la soberbia, la crueldad, el descuidar a los dioses, el tener todas las cosas como vendibles (Sal. BC 10.1-4).

Orosio parece estar plenamente de acuerdo con Salustio cuando señala que "con la destrucción de Cartago y Numancia desaparece entre los romanos la útil rivalidad por estar prevenidos y nace la infame tensión que arranca del ansia de dominio"15
Propio de la historiografía clásica era también su fin pedagógico y educativo. La historia era útil sobre todo por la enseñanza que proporcionaban las vidas de los personajes; su lectura servía para sacar lecciones de ejemplos positivos que debían ser seguidos y malos que, por el contrario, se debían rechazar. Los historiadores romanos le daban a la enseñanza moral una particular importancia; era necesario, entonces, conocer las mores o costumbres de los hombres que ejecutaban las acciones. Tito Livio lo había expresado claramente en su prefacio: "El centro de atención para mí es saber cuál fue la vida, cuáles las costumbres [quae vita, qui mores], por medio de qué hombres (...) fue creado y engrandecido el Imperio" (Livio, praef. 9). La historia debía hacer algo más que contar relatos interesantes, debía entregar también un juicio moral: que las virtudes y los vicios fueran sacados a la luz y conocidos por todos. Esta fama pública sería, según Tácito, también parte de la gloria o de la vergüenza de los actores de la historia: "Tengo decidido no recoger más que las propuestas insignes por su honestidad o notables por su ignominia, lo cual estimo el cometido fundamental del historiador, de manera que no queden en silencio los ejemplos de virtud [ne virtutes sileantur] y para que el miedo a la infamia en la posteridad reprima las palabras y acciones perversas" ${ }^{16}$. Esta intencionalidad ética también es un elemento presente, y con más fuerza si cabe, en el relato histórico de Orosio. Si la historia había sido definida por Cicerón como magistra vitae (Cic. De Or. 2.36), los historiadores cristianos se empeñarían en que sus historias enseñaran no sólo buenos ejemplos, sino que fueran, de alguna manera, magistra vitae aeternae (Ch. Bedouelle, 1993). Es así, entonces, que Orosio narra con esta finalidad ejemplar las acciones del emperador Teodosio, que vence al mismo tiempo a

15 Orosio, Adv. Pag. 5.8.2: Carthagine Numantiaque deleta moritur apud Romanos utilis de provisione conlatio et oritur infamis de ambitione contentio.

16 Cf. Tac. Ann. 3.65: Exequi sententias haud institui nisi insignis per honestum aut notabili dedecore, quod praecipuum munus annalium reor ne virtutes sileantur utque pravis dictis factisque ex posteritate et infamia metus sit. 
los godos y también la guerra civil en la disputa por el legítimo trono del Imperio. "Teodosio pensó", señala Orosio siguiendo la costumbre de algunos historiadores clásicos de presentarse como narrador omnisciente, "que el Estado, que estaba en ruinas por la ira de Dios, debía ser restaurado por la misericordia de Dios; y poniendo toda su confianza en la ayuda de Cristo, venció, agrediéndoles sin parar en muchas y singulares batallas, a los pueblos escitas, enormes en número y temidos por todos nuestros antepasados" (Orosio, Adv. Pag. 7.34.5). Es justamente la piedad de Teodosio, "quien puso su esperanza en Dios [posuit in Deum spem suam]" (Orosio, Adv. Pag. 7.35.2), la que le permite una victoria total sobre sus enemigos y una muerte tranquila con la asistencia divina ${ }^{17}$. Por el contrario, Juliano es puesto como modelo de hombre impío que maquina asechanzas contra los seguidores de Cristo y por ende su vida termina desastrosamente atravesado sorpresivamente por la lanza de un enemigo: "De esta forma, Dios misericordioso desbarató las impías decisiones con la muerte del impío [sic misericors Deus impia consilia impii morte dissoluit]" ${ }^{18}$. En todo momento del relato de Orosio queda claro al lector si el ejemplo que se presenta es digno de imitación o de rechazo. La presencia o ausencia de la virtud de la piedad [pietas], perteneciente al canon tradicional de las virtudes romanas pero ahora en clave cristiana, se presenta aquí casi como la explicación fundamental de los destinos de estos dos emperadores.

Otros aspectos comunes de Orosio con los representantes de la historiografía clásica grecorromana son de un toque más formal, es decir, no se refieren ya al contenido o a la misión que le otorgaban a la historia, sino que más bien aluden a la manera misma en que esta era escrita. Para presentar una narración más ordenada y elegante Orosio utiliza ciertas reglas de la retórica, de alguna manera ejemplificando lo que quiere decir Cicerón cuando afirma que la historia "se trata de una cosa como ninguna otra digna de un orador [opus oratorie maxime]" (Cic. De Leg. 1.5). Toda escritura histórica, también la cristiana, necesitaba de la retórica: los hechos tenían que ser interpretados; el material, organizado; los detalles, seleccionados; los eventos, reconstruidos, y, tal como había dicho Salustio, "las palabras, armonizadas con los hechos [facta dictis exaequanda]" (Sal. BC 3.2).

Uno de estos ideales de la historia retórica que se había constituido en característica común en los historiadores griegos y romanos era el de la brevedad. La brevitas consistía en el difícil arte de decirlo todo con el mínimo de palabras necesarias. Quizá uno de sus primeros representantes fuese el griego Tucídides en su narración sobre la guerra del Peloponeso. Ya en el siglo I a. C. Dionisio de Halicarnaso había comentado la brevitas de Tucídides, alabándolo cuando la brevedad hacia el relato más ágil, pero criticándolo cuando en ciertos pasajes, por ser breve, resultaba incomprensible ${ }^{19}$. En las letras romanas había sido Salustio, consciente imitador de Tucídides, quien hiciera de la brevitas su característica primordial. Séneca habla de la "brevedad oscura" [obscura brevitas] del historiador republicano, y Quintiliano, un poco más tarde, recordaría también "aquella brevedad salustiana" [illa sallustiana brevitas] (Sén. Ep. 114.17; Quint. Inst. Or. 10.31). También Orosio, siguiendo este canon, aspiraría a entregar un relato conciso a pesar de la magnitud de su tarea. En el prólogo de su obra, hablándole a San Agustín, señala: "Me ordenaste, pues, que de todos los registros de historias y anales que puedan tenerse en el momento presente, expusiera en capítulos sistemáticos y breves de un libro [ordinato breviter voluminis textu expli-

17 Para la figura de Teodosio, véase especialmente Orosio, Adv. Pag. 7.34.2-35.23

18 Orosio, Adv. Pag. 7.30.6. Para todas las referencias del emperador Juliano, véase Orosio, Adv. Pag. 7.28.2 y 7.29-15-30.6

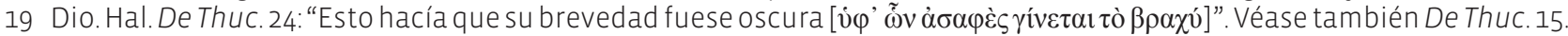


carem] todo lo que encontrase"20. Sin embargo, Orosio será también crítico de la brevitas cuando esta deja lugar a dudas sobre lo que se está diciendo, y así lo expresa en el prólogo del libro tercero cuando señala la dificultad de ser breve en su labor por la cantidad de información de que dispone: "Si en aras de la brevedad paso por alto algunas cosas, pensarán o bien que yo las desconozco o bien que no tuvieron lugar en su época; pero si, por deseo de reseñar todos los hechos, aunque sin detallarlos, hago breves resúmenes, lo haré todo oscuro" ${ }^{21}$. Este es, por ejemplo, el caso de Suetonio, que, en el afán de acortar, hace incomprensible y provoca la queja de Orosio: "En el año noveno de su reinado [de Claudio] cuenta Josefo que Claudio expulsó de Roma a los judíos. Pero a mí lo que me trastorna es lo que dice Suetonio: 'Claudio expulsó de Roma a los judíos que, por culpa de Cristo, estaban continuamente provocando revueltas' (Suet. Claudio 25.4). Con relación a lo cual no se sabe si lo que quiso decir es que ordenó reprimir y castigar a los judíos que se levantaban contra Cristo, o bien que hizo expulsar también a los cristianos como si fueran hombres de una religión semejante" (Orosio, Adv. Pag. 7.6.15).

Orosio, al igual que los oradores e historiadores grecorromanos, busca también conmover [movere] a sus lectores. El despertar emociones en la audiencia era un objetivo legítimo si se quería persuadir. El autor debía suscitar los sentimientos apropiados, es decir, que la narración de los sucesos moviera a la simpatía o antipatía y concordase con lo que realmente había sucedido. Por ejemplo, en el caso del saqueo de Roma por los galos a fines del siglo IV a. C., la descripción dramática de Orosio lleva casi necesariamente a la conclusión de que este saqueo fue peor que el de Alarico en el 410 d. C. La impo- tencia y la desesperación de los romanos al ver su ciudad destruida mueven al lector a "sentir de nuevo" los sufrimientos experimentados en el momento de aquella terrible situación: "Los galos penetran en la ciudad sin defensa, matan a los senadores que permanecen en sus asientos, rígidos a modo de estatuas, y los sepultan, quemados en el incendio de sus casas, con los escombros de sus propios techos. (...) Machacan con hambre, peste, desesperación y miedo a los desafortunados sobrevivientes. (...) Solo quedaba un sucio montón de informes ruinas y, por todas partes, el eco de la triste voz de los que erraban por aquellos lugares caóticos. (...) El horror sacudía los ánimos y el propio silencia aterrorizaba” (Orosio, Adv. Pag. 2.19.7-11). Esta descripción se acerca mucho a la que realiza Tito Livio al final del libro V de su Ab Urbe Condita cuando narra el mismo episodio de la destrucción de Roma por los galos; es más, la similitud hace pensar que puede haber sido la fuente de Orosio para este suceso (cf. Livio, 5.43-8). Y esto nos lleva a considerar otro aspecto propio de la historiografía antigua: su cualidad agonística. El deseo de la emulación y competencia también está presente en la obra de Orosio, tal como había estado en Tucídides compitiendo con sus predecesores (Tuc. 1.22.4), o en Tácito cuando rivaliza con sus colegas señalando que después de la batalla de Accio no había historiadores que pudieran escribir historia propiamente tal, "primero, porque eran ignorantes en materia política ya que no era de su competencia; luego, porque tenían un apasionado deseo de halagar, o también por odio a sus dominadores. Así, entre la hostilidad de un grupo y el servilismo del otro, la posteridad fue ignorada" (Tac. Hist. 1.1). Orosio también se muestra a sí mismo como dando un paso más allá que sus antecesores, los historiadores romanos, pues no

20 Orosio, Adv. Pag. 1. praef. 10: praeceperas ergo, ut ex omnibus qui haberi ad praesens possunt historiarum atque annalium fastis (...) ordinato breviter voluminis textu explicarem. Otros ejemplos donde Orosio habla explícitamente de la brevitas de su obra son: 1.12.1; 3.1.4; 5.17.2; 6.5.11; 6.5.13.

21 Orosio, Adv. Pag. 3. praef: si enim aliqua studio brevitatis omitto, putabuntur aut mihi nunc defuisse aut in illo tunc tempore non fuisse; si vero significare cuncta nec exprimere studens conpendiosa brevitate succingo, obscura faciam. 
solo narra hechos, sino que además los interpreta: "Grandes e innumerables acciones han sido transmitidas detalladamente por muchos autores, y estos, aunque no tenían los mismos motivos, tenían, sin embargo, a su disposición los mismos hechos. Pero es que mientras ellos narraban las guerras, nosotros debemos narrar las desgracias que acompañan las guerras" (Orosio, Adv. Pag. 3. praef. 1).

Otros recursos retóricos como el uso de la inventio, por ejemplo, al dar detalladamente vívidas descripciones de caracteres importantes ${ }^{22}$, o el incluir variados excursos con descripciones geográficas ${ }^{23}$, son utilizados por Orosio de una manera consciente a lo largo de las Historiae: su autor ha tenido el entrenamiento necesario para poder hacer uso de ellos con naturalidad y el público al cual se dirige la obra espera precisamente ese tipo de historia ${ }^{24}$. Orosio escribe como los historiadores grecorromanos y utiliza sus mismos criterios para establecer las cronologías: cuando narra la historia griega sus fechas las calcula con respecto a las Olimpíadas, mientras que para Roma utiliza el clásico Ab Urbe Condita (desde la fundación de la ciudad) de los analistas latinos. Orosio es parte de un Imperio y, aunque el acontecimiento de la Encarnación de Cristo sea para él un hecho trascendental dentro de la historia del mundo, no se le ocurre ponerlo como un hito cronológico que marque un antes y un después ${ }^{25}$. Orosio utiliza el sistema convencional de su tiempo para establecer las cronologías necesarias, en primer lugar porque él está escribiendo principalmente para paganos que se manejan en esos términos, pero también, y quizá sobre todo, justamente porque quiere probar que los acontecimientos seculares prueban la verdad e historicidad del cristianismo: el cristianismo nace y se desarrolla en la historia de los pueblos.

Quizá las mismas razones por las que Orosio utiliza la datación griega o romana son también por las que hace un escaso uso de citas bíblicas. Orosio quiere maximizar el impacto de su obra y es consciente de que los paganos no se dejarían impresionar por su conocimiento de la Sagrada Escritura o por la utilización de otros escritos eclesiásticos. Al contrario, sus fuentes son principalmente paganas, y lo que quiere demostrar no es que estas se equivocan al contar los acontecimientos, sino que no han sido capaces de entender el mensaje subyacente de la historia. Su estrategia al utilizarlas es mostrar que ha sido designio de Dios unir a todos los pueblos bajo un Imperio para facilitar la expansión del cristianismo: Dios ha elegido al Imperio romano como su instrumento para esto. La historia de Roma es para Orosio al mismo tiempo historia universal e historia cristiana. Las tres son inseparables.

\section{3.}

Es precisamente la inseparabilidad de la historia del mundo de la historia cristiana la que hace de Orosio un representante original dentro de su tiempo. El joven sacerdote hispano se propone contar la historia del mundo utilizando las fuentes y relatos que habían sido las bases de la historia tal como la habían narrado

22 Véase por ejemplo la descripción de Semíramis en 1.4.4-8 o de Calígula en 7.5.1-2 y 9-10

23 Siendo el más notable de ellos, sin duda, el extenso capítulo dos del libro I, donde realiza una descripción de toda la situación del orbe conocido; véase 1.2.1-106.

24 Cf. P. van Nuffelen, 2012. Para un tratamiento más detallado sobre las características retóricas de la escritura histórica véase Ch. Fornara, The Nature of History in Ancient Greece and Rome (Los Angeles, 1983); A. Woodman, Rhetoric in Classical Historiography (1988); J. Marincola, Auhtority and Tradition in Ancient Historiography (Cambridge, 1997); Aurell, Balmaceda, Burke y Soza, 2013: 16-24.

25 Como sí lo haría a principios del siglo VI el monje Dionisio el Exiguo (c. 470 - C. 554), que estableció la fecha del nacimiento de Cristo o anno Domini, fundando así el primer año de la "era cristiana". Dionisio habría fijado este año en el 753 ab urbe condita, o desde la fundación de la ciudad de Roma. El sistema del anno Domini se volvería dominante en Europa sólo después de que Beda lo utilizara para fechar los acontecimientos en su Historia Eclesiástica del Pueblo Inglés en el siglo VIII. 
los griegos y romanos paganos, con muy pocas citas bíblicas y referencias a escritores eclesiásticos que podrían haber hecho de la obra un texto para ser leído y entendido solo por cristianos. Al contrario, el encargo que le ha hecho Agustín es justamente probar a los paganos que el cristianismo no es causa de los males actuales del Imperio, como el saqueo de Alarico, sino mostrar que toda la historia Roma así como también la del mundo entero ha estado siempre plagada de corrupción, derrotas y miseria.

Orosio se pone como uno de sus objetivos desmitificar el pasado glorioso romano y con esto se desmarca totalmente de la visión tradicional de la historiografía romana que veía en los hechos heroicos de sus antepasados la razón de la grandeza y eternidad de Roma. Para Orosio, en cambio, es la venida de Cristo al mundo lo que hace que el Imperio se vuelva un lugar menos hostil para vivir: "Aquella época pasada no pudo ser tan desgraciadamente turbia y revuelta sino porque Dios estaba airado y olvidado, y que esta nuestra es tan feliz porque cuenta con un Dios propicio y misericordioso"26. Es la religión cristiana la que, al contrario de lo que señalan sus detractores, ha sido un factor clave en la disminución de los desastres del mundo según Orosio. Esto puede verse incluso hasta en los mismos elementos de la naturaleza que han cambiado su manera de actuar; la misma tierra ha mejorado con la llegada del cristianismo: "En Sicilia (...) el Etna en aquella época vomitaba en frecuentes erupciones con la consiguiente ruina de ciudades y campos; ahora, sin embargo, sólo humea en inocente espectáculo para dar prueba de lo que fue en otro tiempo"27.

La invasión de Roma por Alarico se presenta para Orosio como el ejemplo paradigmático de que la sola presencia de cristianos en una comu- nidad alivia el sufrimiento de todos porque Dios al ver a sus seguidores está más inclinado a la misericordia. El saqueo de Roma del 410 ciertamente había sido un golpe duro para la Iglesia; Jerónimo está horrorizado y escribe: “¿Qué puede estar a salvo si Roma ha caído?”28. Agustín, por su parte, trata el problema insistiendo en la distinción entre la ciudad terrena y la ciudad celeste, poniendo énfasis en esta última y repitiendo una y otra vez que la terrena importa menos (Agustín, Civ. Dei, 1.1-7). Orosio toma un camino distinto; su solución para enfrentar el problema que esta cuestión significa para la fe será, directamente, negar que exista un problema. El saqueo, plantea Orosio, no es algo realmente significativo y, en realidad, se ha producido por la presencia de los paganos en la ciudad, no por los cristianos: el objetivo de Dios ha sido precisamente castigar la impiedad de los romanos ${ }^{29}$. Estemos o no de acuerdo con las conclusiones que saca Orosio, no se puede negar que la táctica de contrastar el saqueo de los godos del $410 \mathrm{~d}$. C. con el de los galos el 390 a. C. es impecable:

En verdad que estos dos saqueos son paralelos y se pueden comparar entre sí: aquel se ensañó con Roma durante seis meses; este ha durado tres días; los galos, tras aniquilar al pueblo y destruir la ciudad, persiguieron incluso el propio nombre de Roma quemándola hasta el final; los godos, tras abandonar sus intenciones de botín, han conducido a sus hordas, sin que estas se dieran cuenta, al refugio de la salvación, es decir, a lugares santos; en aquel caso apenas se puede encontrar un senador que escapara, incluso de los que estaban ausentes; ahora apenas se puede encontrar uno que haya muerto ni siquiera casualmente mientras se escondía. (...) En este desastre de nuestra época ha sido Dios el que más se ha encolerizado y los hombres los que menos, ya que, al hacer Él mismo lo que los hombres no

26 Orosio, Adv. Pag. 2.18.5: neque illa [sc. aetas] nisi irato atque aversato Deo posse tam infeliciter perturbari ac permisceri neque ista sic nisi propitio et miserante conponi.

27 Orosio, Adv. Pag. 2.14.3: ... Aethna ipsa, quae tunc cum excidio urbium atque agrorum crebris eruptionibus aestuabat, nunc tantum innoxia specie ad praeteritorum fidem fumat.

28 Jer. Ep. 123.16. Para el mismo efecto, véase también Ep. 127.11-12; 128.5

29 Para el saqueo de Roma por Alarico, véase, por ejemplo, S. Mitchell, 2007: 89-95, y R. C. Blockley, 1998: 125-8. 
pudieron hacer, ha mostrado la razón por la cual envió a estos enemigos ${ }^{30}$

Para Orosio, Dios interviene directamente en la historia castigando o premiando según corresponda. Las persecuciones de los cristianos, por ejemplo, necesariamente atraen la venganza divina que se manifiesta en plagas, terremotos, sequías. Refiriéndose al periodo inmediatamente posterior a Nerón, Orosio señala que "Roma paga así con la muerte de sus emperadores y con las guerras civiles que por ello se provocan las injurias que recientemente había infligido a la religión cristiana”31. También la persecución de Marco Aurelio, la cuarta después de Nerón, tuvo su propio castigo: "Como consecuencia hubo una epidemia que se extendió por muchas provincias y una peste tan grande asoló a toda Italia que por todas partes las villas, los campos y ciudades se convirtieron en ruinas y en lugares salvajes al quedarse desiertos, sin cultivadores y habitantes"32. La idea que nos dejan estos pasajes es la de un individuo altamente combativo. El instinto de Orosio cuando se confronta con la oposición pagana es el de atacar, no el de conciliar. Señalando la impiedad de los romanos para con el verdadero Dios como la causa de los males, Orosio da vuelta el argumento de su enemigo y lo reduce casi al absurdo.

No se puede negar que la interpretación de la historia de Orosio tiene un toque providencialista. Sin embargo, el hecho de que Dios guíe la historia de los hombres y conozca su futuro no significa que el autor presente la historia del mundo como una simple alegoría de la voluntad de Dios, como podría proponer un providencialismo exacerbado, negando así las causas y los efectos de la libertad de los hombres. Para Orosio, como para muchos historiadores cristianos, era complejo conectar la Providencia divina con la causalidad; muchas veces los conceptos teológicos y los históricos se movían en planos distintos: Ias interrogantes muchas veces no se podían resolver o se solucionaban solo parcialmente, pero no por eso dejaron de plantearse seriamente el papel de Dios en la historia. Orosio señala que, precisamente porque somos producto de la acción de Dios con su creación, somos también objeto de su preocupación providencial, pues “¿quién puede amar más a una obra que aquel que la hizo? y, ¿quién puede administrarla con mayor orden que aquel que la hizo y aprecia?"33. Orosio sostiene que Dios interviene en el mundo y utiliza instrumentos humanos para llevar a cabo su plan. Un ejemplo de este actuar de Dios es el caso de la destrucción del templo de Jerusalén, que fue realizada en el tiempo por el general Tito en el año 70 d. C., pero en verdad había sido la decisión de Dios [arbitrio Dei] la que había determinado que tenía que ser destruido como algo obsoleto y sin sentido. La voluntad de Dios actuó a través de Tito, quien como general triunfante incendió y arrasó con el templo, que desde el día de su primera construcción hasta el día de su última destrucción había estado en pie mil ciento dos años (Orosio, Adv. Pag. 7.9.5-6). También fue Dios el que impidió a Aníbal tomar y destruir Roma (Orosio, Adv. Pag. 4.17.8), y el que

30 Orosio, Adv. Pag. 2.19.13-14: revera pares sunt et conferuntur inter se hae duae captivitates: illa sex mensibus desaeviens et tribus diebus ista transcurrens; Galli exstincto populo urbe deleta ipsum quoque Romae nomen in extremis cineribus persequentes et Gothi relicta intentione praedandi ad confugia salutis, hoc est sanctorum locorum, agmina ignara cogentes; ibi vix quemquam inventum senatorem, qui vel absens evaserit, hic vix quemquam requiri, qui forte ut latens perierit. recte sane conpararim, hunc fuisse ibi servatorum numerum, qui hic fuerit perditorum. plane, quod re proditur, et fatendum est: in hac clade praesenti plus Deum saevisse, homines minus, cum, peragendo ipse quod illi non inplevissent, cur eos miserit demonstravit. Para el saqueo galo, véase Livio, 5.35-42.

31 Orosio, Adv. Pag. 7.8.2: Luit Roma caedibus principum excitatisque civilibus bellis recentes Christianae religionis iniurias El autor se refiere aquí al Ilamado "año de los cuatro emperadores".

32 Orosio, Adv. Pag. 7.15.5: secuta est lues plurimis infusa provinciis, totamque Italiam pestilentia tanta vastavit, ut passim villae, agri atque oppida sine cultore atque habitatore deserta in ruinas silvasque concesserint.

33 Orosio, Adv. Pag. 2.1.2: quis enim magis diligit, quam ille qui fecit? quis autem ordinatius regit, quam is qui et fecit et diligit? 
se sirvió de un pastor de paupérrima condición, Rómulo, para fundar la ciudad de Roma (cf. Orosio, Adv. Pag. 6.1.6).

Quizá es este mismo providencialismo el que hace que las Historiae adversus Paganos reflejen cierto toque de triunfalismo. A pesar de las vicisitudes del momento, Orosio - que escribe solo unos 7 años después del terrible saqueo de Roma que hizo pensar en el fin del Imperio romano- posee la certeza de la victoria final, aunque no sea en este mundo:

Sea el que sea el lugar al que yo llegue como desconocido, no temo un repentino ataque como si fuese un desamparado. Entre los romanos, como dije, soy romano, entre los cristianos soy cristiano, entre los hombres soy hombre; por la ley puedo recurrir al Estado; por la religión, a la conciencia humana; por la idéntica comunidad de naturaleza, a la naturaleza. Para mí ahora, por un tiempo, toda la tierra es, por así decir, mi patria, ya que la verdadera patria, la patria que anhelo, no está de ninguna forma en la tierra ${ }^{34}$

Estas palabras reflejan a la vez su confianza en el triunfo de los aliados de Dios en el mundo, y se constituyen también como un himno a la confianza en la racionalidad de los hombres. En su escritura histórica Orosio manifiesta también un universalismo que se ve expresado no solo en el largo excurso del libro I donde describe toda la tierra conocida en ese entonces, sino más fuertemente en la linealidad que hace de los distintos imperios que han dominado el mundo. Orosio divide o estructura el devenir histórico en una sucesión de cuatro imperios universales que se suceden unos a otros: el babilónico, el macedónico, el cartaginés y el romano. Orosio sigue una tradición conocida al respecto35; sin embargo, añade también un elemento novedoso que es la proyección de la Roma cristiana como un quinto imperio triunfante y que recoge la herencia de los anteriores (cf. Aurell, Balmaceda, Burke, Soza, 2013: 71). Pero tal vez el toque universalista más original de Orosio sea la notable sincronización que realiza del nacimiento de Cristo y el ascenso al poder de Augusto. La "coincidencia" de la aparición de estos dos grandes personajes sirve para subrayar el mensaje de que Roma y su Imperio han sido clave en los planes de Dios para la humanidad. Cristo, príncipe de la paz, nace justo cuando Augusto ha establecido una paz por todo el orbe. La fuerza con que Orosio expresa esta potente idea es de tal magnitud que vale la pena poner la cita completa:

Por el contrario, si es absolutamente indudable que bajo el reinado de César Augusto, tras la paz con los partos, el orbe de la tierra se ha recuperado por primera vez con una paz general y con una nueva tranquilidad, abandonando las armas y olvidando las discordias; si es cierto que se mantiene obediente a las leyes de Roma; que ha preferido el derecho romano a sus propias armas; (...) y finalmente si es cierto que todas las razas, todas las provincias, las innumerables ciudades, los infinitos pueblos y todas las tierras tienen una sola voluntad, sirven con libre y honesto interés a la paz y toman decisiones en pro del bien común, y si es cierto también que, cuando todo esto sucedía en el reinado de César, tenía lugar en el reinado de este mismo César el nacimiento de nuestro Señor Jesucristo en este mundo, está clarísimo, con evidencia absoluta, que, aunque aquellos a los que la envidia empuja a la blasfemia se ven obligados de mala gana a reconocerlo y confesarlo, esta paz y serenísima tranquilidad del mundo se debe no a la grandeza de César, sino al poder del hijo de Dios que nació en la época de

34 Orosio, Adv. Pag. 5.2.5-6: ubicumque ignotus accessero, repentinam uim tamquam destitutus non pertimesco. inter Romanos, ut dixi, Romanus, inter Christianos Christianus, inter homines homo legibus inploro rempublicam, religione conscientiam, communione naturam. utor temporarie omni terra quasi patria, quia quae uera est et illa quam amo patria in terra penitus non est.

35 Pompeyo Trogo había hablado de cuatro imperios y seguramente Orosio lo había seguido a través de Justino —que había escrito los epítomes de Trogo y es una de las fuentes principales de Orosio-. Por otro lado, la teoría de la sucesión de los cuatro imperios era conocida en el mundo cristiano por la profecía del libro de Daniel (Daniel 2.31-45); cf. SánchezSalor, 1982: 35-6; Fear, 2010: 18-20. 
César, y que el propio mundo ha obedecido con general reconocimiento no al emperador de una sola ciudad, sino al creador de todo el orbe.

At vero, si indubitatissime constat sub Augusto primum Caesare post Parthicam pacem universum terrarum orbem positis armis abolitisque discordiis generali pace et nova quiete conpositum Romanis paruisse legibus, Romana iura quam propria arma maluisse spretisque ducibus suis iudices elegisse Romanos, ${ }^{6}$ postremo omnibus gentibus, cunctis provinciis, innumeris civitatibus, infinitis populis, totis terris unam fuisse voluntatem libero honestoque studio inservire paci atque in commune consulere - quod prius ne una quidem civitas unusue populus civium vel, quod maius est, una domus fratrum iugiter habere potuisset ; 7 quodsi etiam, cum imperante Caesare ista provenerint, in ipso imperio Caesaris inluxisse ortum in hoc mundo Domini nostri lesu Christi liquidissima probatione manifestum est: ${ }^{8}$ inviti licet illi, quos in blasphemiam urguebat invidia, cognoscere faterique cogentur, pacem istam totius mundi et tranquillissimam serenitatem non magnitudine Caesaris sed potestate filii Dei, qui in diebus Caesaris apparuit, exstitisse nec unius urbis imperatori sed creatori orbis universi orbem ipsum generali cognitione paruisse, qui, sicut sol oriens diem luce perfundit, ita adveniens misericorditer extenta mundum pace vestierit. quod plenius, cum ad id ipso perficiente Domino ventum fuerit, proferetur (Orosio, Adv. Pag. 3.8.5-8)

Por una parte se muestra como si el cristianismo no hubiera podido existir de no haber sido por la presencia del Imperio romano: habían sido el orden y la paz que Augusto había traído al Imperio los que habían hecho posible el nacimiento de Cristo en el momento adecuado. Para Orosio, Dios había preparado desde el inicio del mundo -y por eso era necesario empezar con Adán- el Imperio en el que convenía que naciera su Hijo ${ }^{36}$. El universalismo a Orosio le viene por partida doble: como romano porque pertenece a un Imperio que se extiende por todo el orbe y como cristiano porque estaba convencido de que Jesucristo había venido a salvar a todos los hombres sin distinción. Una característica peculiar de esta relación entre Imperio romano y la llegada del cristianismo en Orosio es que, además de todas las veces que ha señalado la feliz concurrencia entre Augusto y Cristo, a este último lo presenta como ciudadano romano: "Ha sido nuestro Señor Jesucristo el que, tras hacer crecer por su voluntad esta ciudad y defenderla, la ha llevado al culmen de su poderío, por cuanto desde el momento en que llegó a este mundo quiso, por encima de todo, ser ciudadano de ella, ya que en verdad que debe ser llamado ciudadano romano [civis Romanus] en virtud de su inscripción en el censo romano" (Orosio, Adv. Pag. 6.22.8). Esta afirmación, que es algo único y propio solo de Orosio, se basa posiblemente en una comprensión confusa o errada de la naturaleza de la ciudadanía romana en el siglo I. La concesión universal de la ciudadanía romana a todos los habitantes del Imperio la otorga Caracalla recién en el 212 d. C.; lo que sí era posible antes de esa fecha era que un provincial estuviera inscrito en el censo romano, aunque no por ello poseía la anhelada ciudadanía (cf. A. Fear, 2010: 316; A. Bancalari, 2007). Por otro lado, convertir a Cristo en ciudadano romano muestra, de alguna manera, el optimismo del autor. Orosio ve como si Roma fuera a permanecer siempre, y por eso importa que Cristo pertenezca con todos sus derechos a este Imperio universal y eterno. Esta visión positiva sobre el futuro de Roma contrasta con el pesimismo de otros autores cristianos de la época que presagiaban — sobre todo después de Alarico- la pronta caída del Imperio (cf. P. Heather, 2006).

Es cierto que Orosio presenta su Historiae adversus Paganos como apología y defensa del cristianismo, pero hay que ser cautelosos a la hora de hablar de "historia apologética", como si este carácter incidiera en los criterios de vera- 
cidad y exactitud del relato histórico. Orosio se ve en la necesidad de justificar la historia que escribe, y la inserta en un contexto más amplio: el cristianismo no ha traído males ni ha sido la causa de catástrofes en el Imperio, y para esto basta comparar lo que había sido la historia del mundo antes de la llegada de Cristo con lo que había sucedido después. En la defensa que Orosio hace de la religión cristiana como factor clave en la mitigación de los males, no solo presenta a sus lectores un simple catálogo de todas las calamidades ocurridas a lo largo de la historia de la humanidad, sino que además entrega una narrativa con sentido. Al hacer de Roma el foco principal de sus Historiae, Orosio estratégicamente pone el desarrollo del Imperio como parte del plan divino para la salvación de los hombres, pues es en el Imperio romano donde nace el salvador. Así, la historia romana y la historia cristiana pasan a ser una misma historia y, de paso, Orosio produce un relato que sería más atractivo para su público occidental ${ }^{37}$.

De esta manera, Orosio se presenta como un pionero para la historiografía cristiana del momento en un doble sentido. Por una parte, porque escribe historia de la forma tradicional, es decir, que no difiere formalmente de sus conocidos pares grecorromanos: la manera en que narra su historia, los elementos retóricos, su fin didáctico, todo está presente en Orosio. Tampoco su contenido difiere demasiado de la historiografía clásica: es la narración de la historia de los pueblos más antiguos hasta sus propios días en el Imperio romano. Forma y contenido aparecen como elementos de continuidad entre Orosio y los historiadores griegos y latinos. $Y$ es precisamente este aspecto lo que aparece como novedoso para la historiografía cristiana: las Historiae adversus Paganos puede ser considerada propiamente como una obra de historiografía romana por su contenido y por su forma, de una manera que la Historia Eclesiástica de
Eusebio o las Crónicas de Jerónimo jamás podrían serlo. Por otro lado, Orosio es también un revolucionario porque marca un momento muy especial para la historiografía europea precisamente porque abre la historia secular al análisis cristiano. La insistencia de Orosio en insertar el cristianismo dentro de la historia del mundo lo aleja del modelo judío, de narrar una historia de "pueblo elegido" y como separado de los demás. Orosio no quiere historias paralelas: cristianismo y mundo recorren un mismo camino. Con la historia de Orosio se evita la dicotomía de mirar y tratar a los cristianos como si no fueran de este mundo, sortea el riesgo de apartarlos, de hacerlos formar un grupo distinto, o aislarlos de los demás. Orosio, al contrario, escribe bajo las reglas literarias de los paganos y para ser leído por los paganos, y a ellos les comunica el mensaje de que el cristianismo es un fenómeno de la historia universal que transforma la manera de mirar el mundo: Ia venida de Cristo a la tierra afecta el sentido de la historia desde dentro, en su totalidad y para siempre.

La obra de Orosio fue única en su tiempo. Mientras que otros historiadores cristianos habían compuesto historias de la Iglesia como Eusebio o metahistorias de la salvación como Agustín, Orosio produjo una historia del mundo secular vista desde una perspectiva cristiana, y es justamente la combinación de este tema, conocido y aceptado por todos, con una nueva interpretación ideológica, lo que hace que se convierta en un gran éxito en la Edad Media. Las Historiae de Orosio fueron citadas por todo tipo de autores desde su publicación. Gracias a esto se conservaron numerosos manuscritos repartidos por toda Europa y llegó a ser una de las principales obras para el estudio de la historia antigua durante la Edad Media y hasta el Renacimiento. Con su obra, Orosio muestra que historiadores como el griego Tucídides o el romano Tácito seguirían siendo autoridades históricas 
válidas también para los cristianos; que no eran necesarios los intentos de "cristianizar" la historia política tradicional, sino de transformar el espíritu de la historia pagana para entenderla con sentido cristiano. Con sus Historias contra los Paganos, Orosio revoluciona la escritura histórica cristiana haciéndola formar parte de la tradición grecorromana tanto en contenido como en estilo de una manera original, como no habían hecho hasta entonces los historiadores cristianos. Pero Orosio también revoluciona la historiografía latina interpretando la historia de Roma con un sentido novedoso que la hace partícipe de una misión divina y universal.

\section{Bibliografía citada}

Adler, William, 2008: "Early Christian Historians and Historiography" en Susan Ashbrook y David Hunter (eds.): The Oxford Handbook of Early Christian Studies, Oxford: Oxford University Press, 584-602.

Arnaud-Lindet, Marie-Pierre, 1990: Orose: Histoires (contre les païens), Paris: Belles Lettres.

Ashbrook, Susan y David Hunter (eds.), 2008: The Oxford Handbook of Early Christian Studies, Oxford: Oxford University Press.

Aurell, Jaume, Catalina Balmaceda, Peter Burke y Felipe Soza, 2013: Comprender el Pasado: una historia de la escritura y el pensamiento histórico, Madrid: Akal.

Bancalari, Alejandro, 2007: Orbe Romano e Imperio Global: Ia Romanización desde Augusto a CaracaIla, Santiago: Universitaria.

Bedouelle, Guy, 1993: La Historia de la Iglesia, Valencia: Edicep.

Blockley, R. C, 1998: "The Dynasty of Theodosius" en Averil Cameron y Peter Garnsey (eds.): The Cambridge Ancient History, volumen 13, Cambridge: Cambridge University Press, 111-137.
Cameron, Averil y Peter Garnsey (eds.), 1998: The Cambridge Ancient History, volumen 13 Cambridge: Cambridge University Press.

FeAr, Andy, 2005: "The Christian Optimism of PauIus Orosius" en David Hook (ed.): From Orosius to the Historia Silense: Four Essays on the Late Antique and Early Medieval Historiography of the Iberian Peninsula, Manchester: Hiplam, 1-16.

FeAR, Andy, 2010a: Orosius, Seven Books of History against the Pagans, Liverpool: Liverpool University Press.

Fear, Andy, 2010b: "Orosius and Escaping from the Dance of Doom" en Peter LidDel y Andy Fear: Historiae Mundi: Studies in Universal Historiography, London: Duckworth, 176-88.

FeldherR, Andrew y Grant Hardy (eds.), 2011: The Oxford History of Historical Writing: Beginning to $A D$ 600, Oxford: Oxford University Press.

Fornara, Charles, 1983: The Nature of History in Ancient Greece and Rome, Los Angeles: University of California Press.

GAUGE, Valérie, 1998: "Les routes d'Orose et les reliques d'Etienne”, Antiquité Tardive 6, 265-86.

Heather, Peter, 2006 [2005]: La Caída del Imperio Romano, Barcelona: Crítica.

Hook David (ed.), 2005: From Orosius to the Historia Silense: Four Essays on the Late Antique and Early Medieval Historiography of the Iberian Peninsula, Manchester: Hiplam.

LIDDEL, Peter y Andy FeAR, 2010: Historiae Mundi: Studies in Universal Historiography, London: Duckworth.

Marasco, Gabriele (ed.), 2003: Greek and Roman Historiography in Late Antiquity: Fourth to Sixth Century $A D$, Leiden: Brill.

MarinCOLA, John, 1997: Authority and Tradition in Ancient Historiography, Cambridge: Cambridge University Press. 
Martínez Cavero, Pedro, 2002: El pensamiento histórico y antropológico de Orosio, Murcia: Universidad Área de Historia Antigua.

Mitchell, Stephen, 2007: A History of the Later Roman Empire, Malden y Oxford: Blackwell Publishing.

Momigliano, Arnaldo, 1989 [1963]: "Historiografía pagana y cristiana en el siglo IV" en Arnaldo Momigliano (ed.): El Conflicto entre el Paganismo y el Cristianismo en el siglo IV, Madrid: Alianza, 95-111.

Rousseau, Philip, (ed.), 2012: A Companion to Late Antiquity, Malden y Oxford: Wiley-Blackwell.

Sánchez- Salor, Eustaquio, 1982: Orosio: Historias, Madrid: Gredos.

Torres Rodriguez, Casimiro, 1985: Paulo Orosio. Su vida y sus obras, La Coruña: Fundación Pedro Barrie de la Maza Conde de Fenosa.

Van Nuffelen, Peter, 2010: "Theology versus Genre? The universalism of Christian Historiography in Late Antiquity" en Peter Liddel y Andrew Fear (eds.): Historiae Mundi: Studies in Universal Historiography, London: Duckworth, 162-175.

Van Nuffelen, Peter, 2012: Orosius and the Rhetoric of History, Oxford: Oxford University Press.

Vilella, Josep, 2000: "Biografía crítica de Orosio", Jahrbuch für Antike und Cristentum 43, 94-121.

WhitBy, Michael, 2011: "Imperial Christian Historiography" en Andrew FeLDHERR y Grant HaRDY (eds.): The Oxford History of Historical Writing: Beginning to $A D$ 600, Oxford: Oxford University Press, 346-70.

Woods, David, 2012: "Late Antique Historiography: a Brief History of Time" en Philip Rousseau, (ed.): A Companion to Late Antiquity, Malden and Oxford: Wiley-Blackwell, 357-71.

Woodman, Antony, 1988: Rhetoric in Classical Historiography, Sidney: Croom Helm.
Zecchinl, Giuseppe, 2003: "Latin Historiography: Jerome, Orosius and the Western Chronicles" en Gabriele Marasco (ed.): Greek and Roman Historiography in Late Antiquity: Fourth to Sixth Century $A D$, Leiden: Brill, 317-345. 